Cite this: Phys. Chem. Chem. Phys., 2014, 16, 11527

Received 21st March 2014, Accepted 16th April 2014

DOI: $10.1039 / c 4 c p 01233 j$

www.rsc.org/pccp

\title{
Effect of gamma irradiation on poly(vinyledene difluoride)-lithium bis(oxalato)borate electrolyte
}

\author{
Mimi Hayati Abdul Rahaman, ${ }^{a}$ Mayeen Uddin Khandaker, ${ }^{a}$ Ziaul Raza Khan, ${ }^{b}$ \\ Mohd Zieauddin Kufian, ${ }^{c}$ Ikhwan Syafiq Mohd Noor ${ }^{c}$ and Abdul Kariem Arof*c
}

\begin{abstract}
A poly(vinyledene difluoride)-lithium bis(oxalato)borate solid polymer electrolyte prepared by a solvent casting method has been irradiated with different doses of gamma-rays. Differential scanning calorimetry reveals that the polymer electrolyte irradiated with $35 \mathrm{kGy}$ of $\gamma$-rays is the most amorphous sample. This is also supported by the results obtained from X-ray diffraction. The Fourier transform infrared spectrum of each irradiated sample has been deconvoluted in the wavenumber region between 1830 and $1758 \mathrm{~cm}^{-1}$ in order to predict the percentage of free and contact ions in the samples. The sample exposed to 35 kGy of $\gamma$-rays contains the highest percentage of free ions and the lowest amount of contact ions. This sample also exhibits the highest room temperature conductivity of $3.05 \times 10^{-4} \mathrm{~S} \mathrm{~cm}^{-1}$, which is $15 \%$ higher relative to the virgin sample. The number density of free ions is observed to have more control on the conductivity variation with the $\gamma$-radiation dose compared to ionic mobility. This study confirms that $\gamma$-irradiation can be a potential way to obtain highly conductive and mechanically stable polymer electrolytes.
\end{abstract}

\section{Introduction}

The use of radiation in the study of polymer electrolytes has great importance because it helps in achieving some desired improvements in the properties of the electrolytes. The irradiation of polymeric materials with ionizing radiation leads to the formation of very reactive intermediate products such as excited states, ions and free radicals which can result in rearrangements or formation of new bonds. ${ }^{1}$ The degree of these transformations depends on the structure of the polymer and the conditions of treatment before, during and after irradiation. Thorough control of all of these factors facilitates the modification of polymers by radiation processes. Nowadays, the modification of polymers covers radiation cross-linking, radiation induced polymerization (graft polymerization and curing) and the degradation of polymers.

Radiation can penetrate a polymer, break the polymer chains and create free radicals. These free radicals may create crosslinks with adjacent molecules and recombine. Generally, materials having cross-linked conditions show long term performances in various aspects. Often the two processes (degradation and cross-linking) occur simultaneously, and the outcome of the

\footnotetext{
${ }^{a}$ Applied Radiation Laboratory, Department of Physics, Faculty of Science, University of Malaya, 50603 Kuala Lumpur, Malaysia

${ }^{b}$ Low Dimensional Materials Research Centre, Department of Physics, Faculty of Science, University of Malaya, 50603 Kuala Lumpur, Malaysia ${ }^{c}$ Centre for Ionics University of Malaya, Department of Physics, Faculty of Science, University of Malaya, 50603 Kuala Lumpur, Malaysia.

E-mail: akarof@um.edu.my; Fax: +60379674146; Tel: +60379674085
}

process is determined by a competition between the reactions. ${ }^{1,2}$ Oxidation and degradation occur gradually with increasing radiation dose. Different polymer electrolytes have different effects to radiation depending on the chemical bonds in the polymers. Different studies on the effect of ionizing radiation on polymers reveal a variety of structural modifications such as main chain scission, intermolecular crosslinking, creation of unsaturated bonds, formation of volatile fragments and creation of carbonaceous clusters. ${ }^{3,4}$ Gamma irradiation treatment provides a unique way to modify the chemical, structural, optical, mechanical and electrical properties of the polymer by causing irreversible changes in their macromolecular structure. ${ }^{5,6}$ Such irradiation may produce electrons and low energy photons which are responsible for the modification of the material.

Radiation also affects dielectric properties that are of particular interest to science and technology since dielectrics have many applications in modern engineering. ${ }^{7-10}$ The effect of ionizing radiation on dielectric properties of polymers has been studied by several researchers. ${ }^{11-13}$ The dielectric property has been found to depend strongly on the degree of crystallinity as well as on the manner in which a particular degree of crystallinity has been attained. ${ }^{14-16}$ It is well-known that irradiation treatment enhances the electrical conductivity in insulating polymers. This increase in ionic conductivity is because of fairly high electron freedom. In many researches, it is found that the polymer electrolyte breaks down at very high radiation doses. However, the threshold dose which a polymer is able to withstand before breakdown depends greatly on the chemical structure of the polymers. Indeed, below the destructive level of 
exposure, radiation treatment can impart numerous benefits to the polymer systems and enhance their properties. ${ }^{17,18}$

Over the last four decades, ion-conducting polymers have been tremendously studied due to their potential application as the electrolytes in electrochemical devices. Various efforts have been devoted to develop polymer electrolytes (PE) since liquid electrolytes (LE) are known to give problems in devices. ${ }^{19}$ As lithium-ion batteries continue to penetrate the battery market especially those related to portable gadgets such as notebook computers, camcorders, and telecommunication equipment, there are intense research and development efforts toward raising the technology performance. $\mathrm{LiBOB}$ meets a number of criteria required of salts for lithium-ion cells: (i) ability to form a stable solid electrolyte interphase (SEI) layer; (ii) good stability over a wide potential window; (iii) acceptable solubility in alkyl carbonate solvents such as ethylene carbonate (EC), propylene carbonate (PC), and so forth; (iv) high conductivity in various aprotic solvents; and (v) ability to sustain a good cycling. ${ }^{20}$ Thus, the use of a salt such as lithium bis(oxalato)borate (LiBOB) was chosen in this work.

Poly(vinyledene difluoride) or PVDF is suggested as the polymer host in this work. A PVDF based polymer electrolyte with LiBOB salt was prepared by a solution casting technique. PVDF is a widely studied semicrystalline polymer. The PVDF films, as well as their intrinsic physical properties, have been the subject of numerous publications. ${ }^{21-24}$ In this communication, we report the effects of gamma irradiation on the ionic conductivity of a PVDF-LiBOB polymer electrolyte system. The $\gamma$-radiation dose was varied from 10 to $50 \mathrm{kGy}$. The changes produced by the induced $\gamma$-rays (if any) are detected by differential scanning calorimetry (DSC), Fourier transform infrared (FTIR) spectroscopy and impedance spectroscopy (IS). Although a lot of work has been done to investigate the effect of $\gamma$-irradiation on PVDF polymers, the dependencies of the investigated parameters related to polymer electrolytes due to $\gamma$-irradiation has not been completely understood so far. It is the aim of this paper to shed some light on conductivity variation with increasing doses of $\gamma$-radiation.

\section{Experimental}

\subsection{Sample preparation}

The analytical grade poly(vinylidene difluoride) or PVDF $\left(M_{\mathrm{W}}=2.7 \times 10^{5} \mathrm{~g} \mathrm{~mol}^{-1}\right)$, lithium bis(oxalato)borate (LiBOB) and $N$-methyl-2-pyrrolidone (NMP) were used for sample preparation. The electrolyte polymer films were prepared by the solution casting technique. $1 \mathrm{~g}$ of PVDF was dissolved in $15 \mathrm{~mL}$ of NMP as a solvent. The mixture was stirred at $60{ }^{\circ} \mathrm{C}$ until a homogenous solution was obtained. $30 \mathrm{wt} \%$ of LiBOB salt was added into the solution and stirring was continued for another 2 hours. The homogeneous solution was then cast into a glass petri dish and dried at $60{ }^{\circ} \mathrm{C}$ in a vacuum oven for 1 to 2 days to form free standing films.

\subsection{Gamma irradiation}

The samples were irradiated in air in a conventional gamma-ray chamber at the Applied Radiation Laboratory, University of
Malaya, using a cobalt-60 $\left({ }^{60} \mathrm{Co}\right)$ source with a dose rate of 3.34 Gy $\min ^{-1}$. The samples were exposed to $\gamma$-ray doses of 10, 25, 35, 40 and $50 \mathrm{kGy}$.

\subsection{Differential scanning calorimetry (DSC)}

DSC was carried out using DSC Q200 equipment from TA Instruments to determine the glass transition temperature $\left(T_{\mathrm{g}}\right)$ and melting temperature $\left(T_{\mathrm{m}}\right)$ of non-irradiated and irradiated samples. About $\sim 5 \mathrm{mg}$ of the sample was sealed in aluminum pans and heated from -90 to $190{ }^{\circ} \mathrm{C}$ under nitrogen flow at a heating rate of $10{ }^{\circ} \mathrm{C} \mathrm{min}^{-1}$.

\subsection{X-ray diffraction (XRD)}

$\mathrm{XRD}$ was carried out to determine the effect of gamma radiation on the crystalline/amorphous nature of the samples. X-ray diffractograms of all samples were recorded using an Olympus BTX Benchtop diffractometer from a 2 theta angle of $5^{\circ}$ to $45^{\circ}$.

\subsection{Fourier transform infrared (FTIR) spectroscopy}

The effect of gamma radiation on the structure of the samples can be determined by using FTIR spectroscopy. A Thermo Scientific model Nicolet iS10 spectrometer was used to record the IR spectra of the samples. The spectrum was recorded in the transmittance mode between 650 and $4000 \mathrm{~cm}^{-1}$ with a resolution of $4 \mathrm{~cm}^{-1}$.

\subsection{Impedance spectroscopy}

The impedance measurements were performed using the HIOKI 3532-50 LCR Hi-Tester in the frequency range from $50 \mathrm{~Hz}$ to $5 \mathrm{MHz}$. The sample was sandwiched between two stainless steel blocking electrodes of $2 \mathrm{~cm}$ diameter and measured at room temperature (298 K). A graph of negative imaginary impedance against real impedance was then plotted. The bulk resistance, $R_{\mathrm{b}}$, was obtained from the intercept of the plot with the real impedance axis. The conductivity, $\sigma$, of the sample was calculated using the following equation:

$$
\sigma=\frac{t}{A \times R_{\mathrm{b}}}
$$

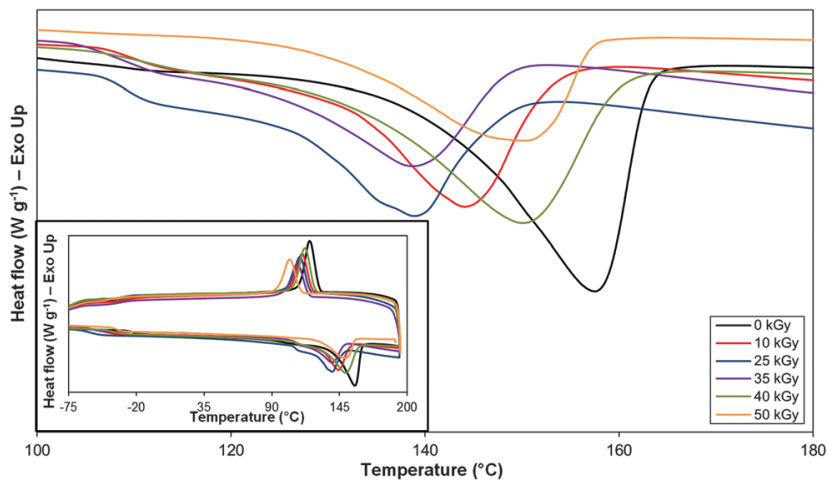

Fig. 1 The melting point, $T_{m}$, peaks of the PVDF-LiBOB electrolyte with different $\gamma$-radiation doses. The inset figure exhibits the DSC of the PVDF$\mathrm{LiBOB}$ polymer electrolyte in full scale cycles. 
Table $1 T_{g}, T_{m}, \Delta H_{m}$ and $\chi_{c}$ values of PVDF-LiBOB electrolytes with different $\gamma$-radiation doses from DSC

\begin{tabular}{llllr}
\hline Dose $(\mathrm{kGy})$ & $T_{\mathrm{g}}\left({ }^{\circ} \mathrm{C}\right)$ & $T_{\mathrm{m}}\left({ }^{\circ} \mathrm{C}\right)$ & $\Delta H_{\mathrm{m}}\left(\mathrm{J} \mathrm{g}^{-1}\right)$ & $\chi_{\mathrm{c}}(\%)$ \\
\hline 0 & -22.66 & 157.5 & 777.1 & 100.0 \\
10 & -46.69 & 144.1 & 482.4 & 62.1 \\
25 & -58.08 & 139.0 & 358.1 & 46.1 \\
35 & -58.17 & 138.7 & 350.9 & 45.2 \\
40 & -36.74 & 149.9 & 440.7 & 56.7 \\
50 & -36.09 & 150.1 & 443.5 & 57.1
\end{tabular}

$T_{\mathrm{g}}=$ glass transition temperature, $T_{\mathrm{m}}=$ melting temperature, $\Delta H_{\mathrm{m}}=$ enthalpy of melting, and $\chi_{\mathrm{c}}=$ degree of crystallinity.

Here $t$ is the sample thickness and $A$ is the electrode-electrolyte contact area.

\section{Results and discussion}

\subsection{Differential scanning calorimetry (DSC)}

The DSC thermograms of PVDF-LiBOB electrolytes with different $\gamma$-radiation doses are shown in Fig. 1. The thermal properties of the polymer electrolyte showed significant changes in the melting temperature, $T_{\mathrm{m}}$, upon $\gamma$-irradiation. The $T_{\mathrm{m}}$ of virgin samples is observed at $157.5{ }^{\circ} \mathrm{C}$. Irradiating the samples with $\gamma$-radiation up to $35 \mathrm{kGy}$ gradually decreased the $T_{\mathrm{m}}$ of the sample. Beyond this dose of $\gamma$-radiation, $T_{\mathrm{m}}$ of the sample is observed to increase. $T_{\mathrm{m}}$ is related to the degree of crystallinity. It has been reported that the shift of $T_{\mathrm{m}}$ towards lower temperature increases the amorphousness of the sample. ${ }^{25}$ This can be estimated by calculating the relative degree of crystallinity, $\chi_{c}$, from the enthalpy of the melting of the sample using eqn (2):

$$
\chi_{\mathrm{c}}(\%)=\frac{\Delta H_{\mathrm{m}}}{\Delta H_{\mathrm{m}}^{0}} \times 100 \%
$$

Here $\Delta H_{\mathrm{m}}$ is the melting enthalpy of the sample and $\Delta H_{\mathrm{m}}^{0}$ is the melting enthalpy of the polymer host. In this work, the non-irradiated sample is considered $100 \%$ crystalline $\left(\Delta H_{\mathrm{m}}^{0}=\right.$ $777.1 \mathrm{~J} \mathrm{~g}^{-1}$ ) so that the variation in the degree of crystallinity can be easily determined. Table 1 lists the thermal parameters and the relative degree of crystallinity of all samples.
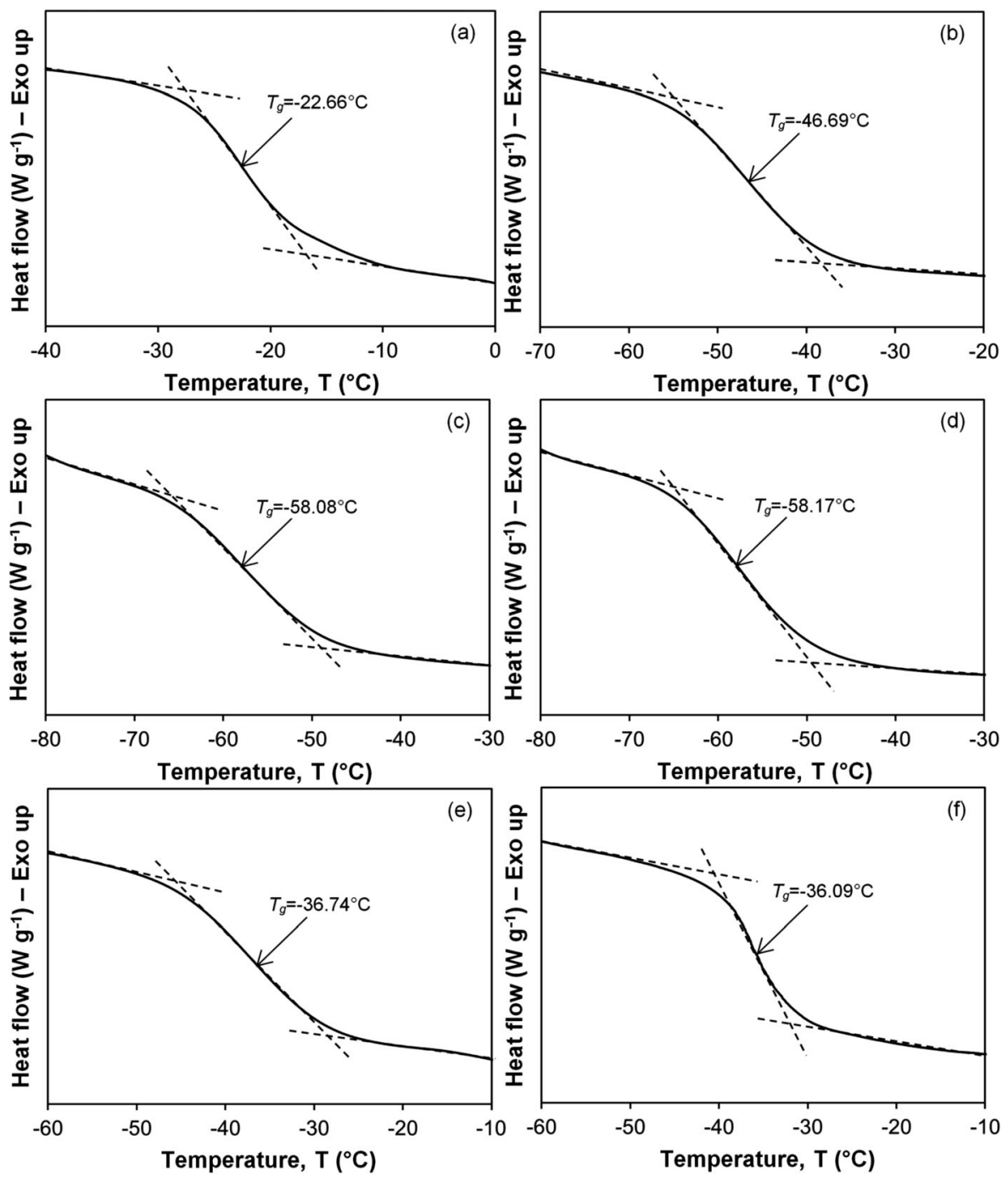

Fig. 2 Glass transition temperature, $T_{g}$, of the PVDF-LiBOB electrolyte with (a) 0, (b) 10, (c) 25, (d) 35, (e) 40 and (f) 50 kGy of $\gamma$-irradiation. 


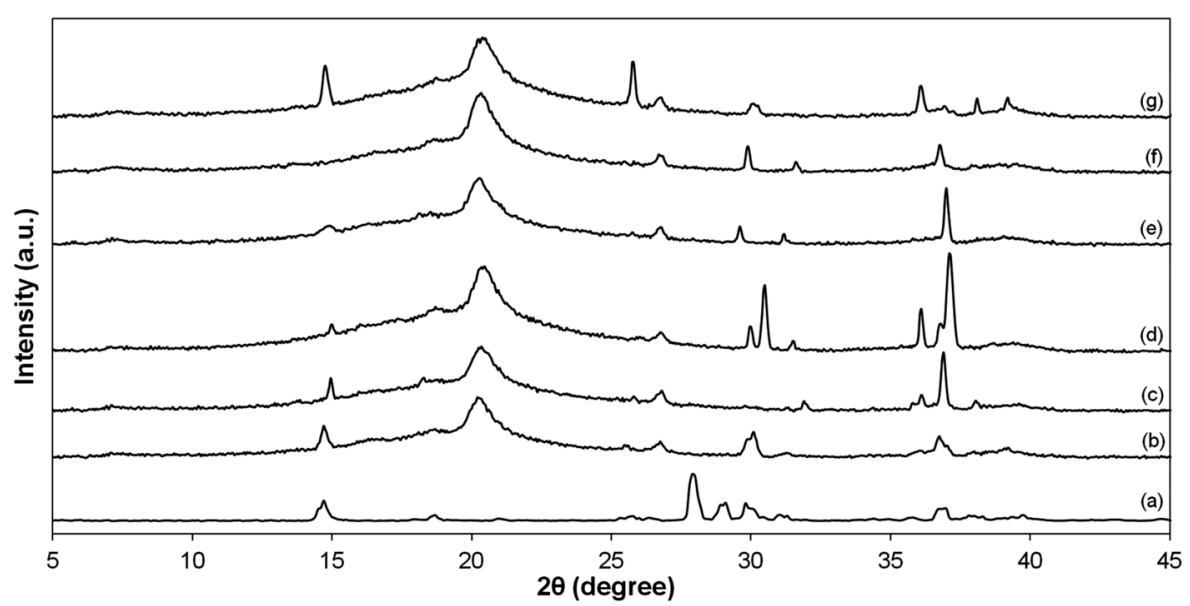

Fig. 3 XRD patterns of (a) LiBOB salt, and the PVDF-LiBOB electrolyte with (b) 0, (c) 10, (d) 25, (e) 35, (f) 40 and (g) 50 kGy of $\gamma$-irradiation.

From Table 1, the sample which is most amorphous is represented by the lowest degree of crystallinity. The sample irradiated with $35 \mathrm{kGy}$ of $\gamma$-rays showed the lowest crystallinity. The decrease in crystallinity may be due to the scissoring of polymer bonds upon $\gamma$-irradiation resulting in an increase in the disorder and amorphousness of the polymer electrolyte.

The DSC thermograms showing glass transition temperature $\left(T_{\mathrm{g}}\right)$ of the PVDF-LiBOB electrolyte with different $\gamma$-radiation doses are illustrated in Fig. 2. The $T_{\mathrm{g}}$ of the virgin PVDF-LiBOB electrolyte is observed at $-22.66^{\circ} \mathrm{C}$. Irradiating the virgin PVDFLiBOB electrolyte up to $35 \mathrm{kGy}$ of $\gamma$-rays decreased the $T_{\mathrm{g}}$ values to $-58.17{ }^{\circ} \mathrm{C}$. Evidence obtained from semicrystalline synthetic polymers showed that as the degree of crystallinity increased, $T_{\mathrm{g}}$ also increased. ${ }^{26}$ Conversely, as the ratio of amorphous to crystalline regions increased, $T_{\mathrm{g}}$ should decrease. The samples irradiated with 40 to $50 \mathrm{kGy}$ of $\gamma$-rays exhibited an increase in $T_{\mathrm{g}}$ from -36.74 to $-36.09{ }^{\circ} \mathrm{C}$. This inferred that an increase in the gamma dose can initiate polymer cross-linking. Polymer cross-linking can
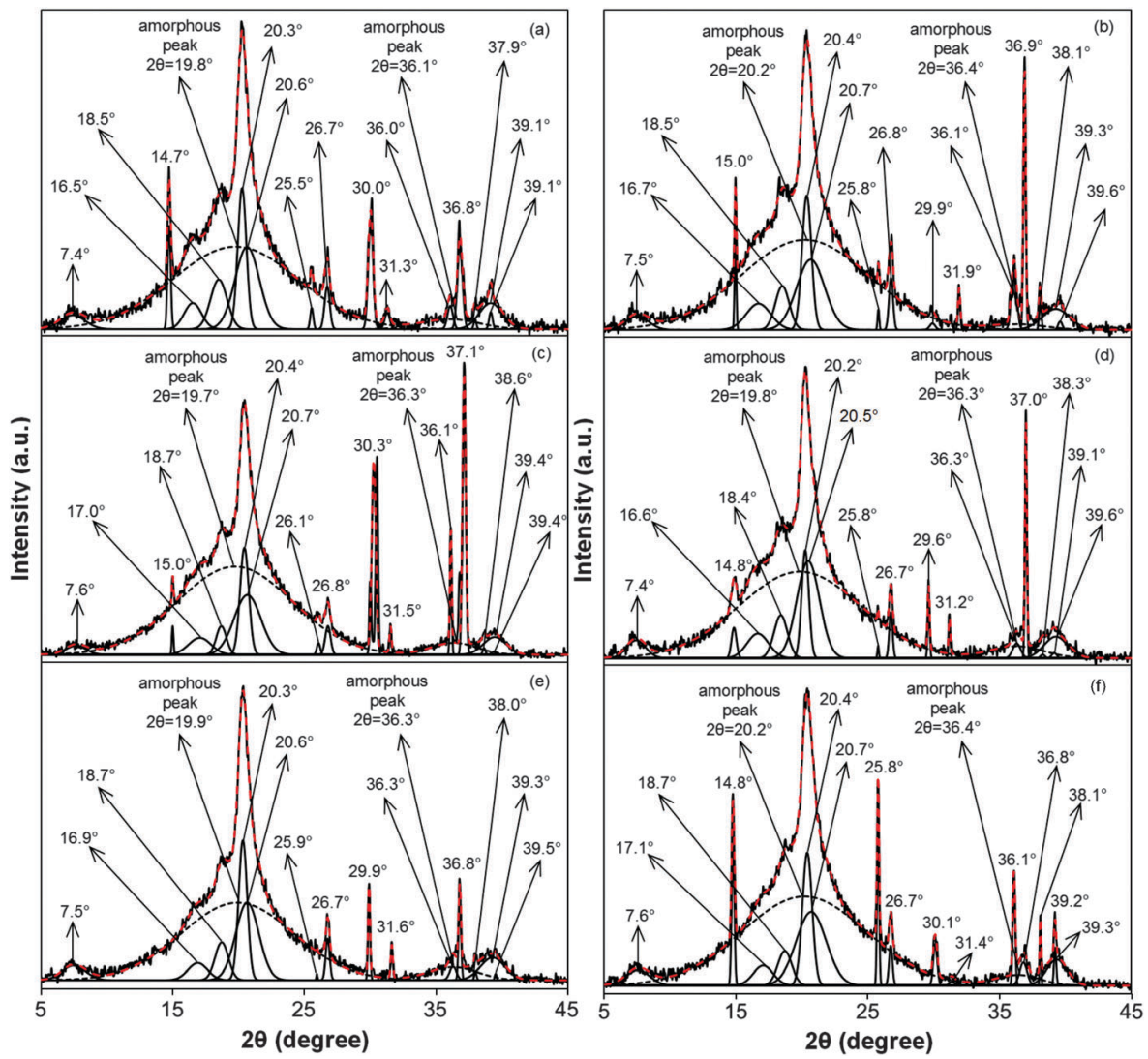

Fig. 4 XRD deconvolution of the PVDF-LiBOB electrolyte with (a) 0, (b) 10, (c) 25, (d) 35, (e) 40 and (f) 50 kGy of $\gamma$-irradiation. 
Table $2 A_{\mathrm{c}}, A_{\mathrm{a}}$ and $\chi_{\mathrm{c}}$ values of PVDF-LiBOB electrolytes with different $\gamma$-radiation doses from XRD

\begin{tabular}{llll}
\hline Doses (kGy) & $A_{\mathrm{c}}$ & $A_{\mathrm{a}}$ & $\chi_{\mathrm{c}}(\%)$ \\
\hline 0 & 3208.83 & 4774.66 & 40.19 \\
10 & 3317.62 & 5623.12 & 37.11 \\
25 & 4470.59 & 7927.34 & 36.06 \\
35 & 3070.27 & 5628.83 & 35.29 \\
40 & 3279.43 & 5591.13 & 36.97 \\
50 & 4108.89 & 6891.66 & 37.35
\end{tabular}

$A_{\mathrm{c}}=$ area of crystalline region, $A_{\mathrm{a}}=$ area of amorphous region, and $\chi_{\mathrm{c}}=$ degree of crystallinity.

result in an increase in localized crystallinity that can impede ionic mobility and lead to a decrease in conductivity.

\subsection{X-ray diffraction (XRD)}

$\mathrm{XRD}$ is a powerful technique to study the structure of the present samples. The X-ray diffraction patterns of LiBOB salt, non-irradiated and irradiated PVDF-LiBOB complexes with different $\gamma$-radiation doses are shown in Fig. 3. It is reported that the PVDF semicrystalline polymer has four crystalline peaks centered at $2 \theta$ angles of $18.2^{\circ}$ [100], $19.8^{\circ}$ [020], $26.6^{\circ}$ $[110]$ and $38.6^{\circ}[021] .^{27}$ The complexation between the PVDF polymer and the LiBOB salt shifts the position of crystalline peaks of PVDF and the characteristic peaks due to LiBOB salt can be observed by deconvoluting the XRD diffractogram of PVDF-LiBOB electrolytes.

Fig. 4 shows the XRD deconvolution of the PVDF-LiBOB electrolyte with different gamma irradiation doses. The crystalline peaks of PVDF are observed at $2 \theta=\sim 18.5^{\circ}, \sim 20.6^{\circ}, \sim 26.7^{\circ}$ and $\sim 39.1^{\circ}$. The other sharp and narrow peaks observed at $2 \theta=\sim 7.4^{\circ}, \sim 14.7^{\circ}, \sim 16.5^{\circ}, \sim 20.3^{\circ}, \sim 25.5^{\circ}, \sim 30.0^{\circ}, \sim 31.3^{\circ}$, $\sim 36.0^{\circ}, \sim 36.8^{\circ}, \sim 37.9^{\circ}$ and $\sim 39.1^{\circ}$ are the crystalline peaks of
LiBOB salts. ${ }^{28}$ The broad halos at $2 \theta=\sim 19.8^{\circ}$ and $\sim 36.1^{\circ}$ represent the amorphous phase of the samples. The shifts in the crystalline peak position of PVDF from that reported in ref. 27 to that observed in Fig. 4 indicate the formation of polymer-salt complexes.

The degree of crystallinity of the sample can also be determined from XRD deconvolution. The degree of crystallinity, $\chi_{c}$, can be calculated using eqn (3): ${ }^{29}$

$$
\chi_{\mathrm{c}}(\%)=\frac{A_{\mathrm{c}}}{A_{\mathrm{c}}+A_{\mathrm{a}}} \times 100 \%
$$

Here, $A_{\mathrm{c}}$ is the area under the peaks representing the total crystalline region and $A_{\mathrm{a}}$ is the area under the peaks representing the total amorphous region. Table 2 lists the values of $A_{\mathrm{c}}, A_{\mathrm{a}}$ and $\chi_{\mathrm{c}}$ of PVDF-LiBOB electrolytes with different $\gamma$-radiation doses. It is observed that increasing the gamma irradiation up to $35 \mathrm{kGy}$ increases the amorphous nature of the electrolyte. Beyond this gamma irradiation, the sample becomes more crystalline.

\subsection{FTIR spectrum}

Radiation induces structural changes in polymers and infrared absorption (FTIR) spectroscopy is one of the analytical techniques used for the study of such changes in these systems. The FTIR spectra of non-irradiated and irradiated PVDF-LiBOB complexes recorded between 1500 and $800 \mathrm{~cm}^{-1}$ for doses of $0,10,25,35,40$ and $50 \mathrm{kGy}$ are shown in Fig. 5 . Table 3 lists the main FTIR peaks of PVDF-LiBOB and their possible assignments. $^{30}$

It is reported that exposing PVDF to $\gamma$-irradiation increases the intensity of the polymer peaks. ${ }^{31}$ This can be proven by considering the band assigned to PVDF characteristics between 1220 and $1135 \mathrm{~cm}^{-1}$. Fig. 6 shows the FTIR deconvolution of

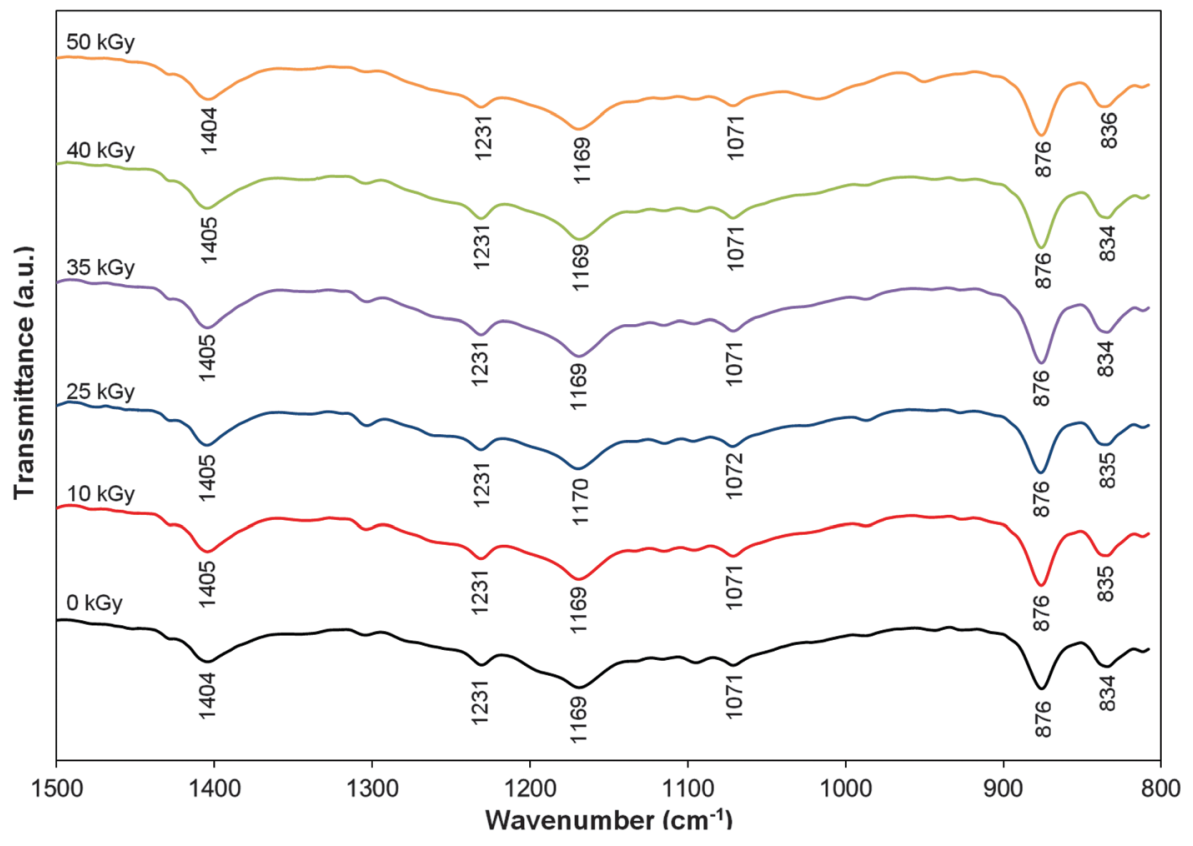

Fig. 5 FTIR spectra of the PVDF-LiBOB electrolyte with different $\gamma$-doses. 
Table 3 The main FTIR peaks of PVDF-LiBOB and their possible assignments

\begin{tabular}{ll}
\hline Wavenumber $\left(\mathrm{cm}^{-1}\right)$ & Assignments \\
\hline 834 & $v_{\mathrm{a}}\left(\mathrm{CF}_{2}\right)$ of PVDF \\
876 & $v_{\mathrm{a}}(\mathrm{C}-\mathrm{C})$ and $v_{\mathrm{s}}\left(\mathrm{CF}_{2}\right)$ of PVDF \\
1071 & $v_{\mathrm{a}}(\mathrm{C}-\mathrm{C}), w\left(\mathrm{CF}_{2}\right)$ and $w\left(\mathrm{CH}_{2}\right)$ of PVDF \\
1169 & $v_{\mathrm{s}}\left(\mathrm{CF}_{2}\right)$ and $t\left(\mathrm{CH}_{2}\right)$ of PVDF \\
1231 & $v_{\mathrm{a}}\left(\mathrm{CF}_{2}\right)$ and $\left[w\left(\mathrm{CH}_{2}\right)\right]$ of PVDF \\
1404 & $w\left(\mathrm{CH}_{2}\right)$ and $v_{\mathrm{a}}(\mathrm{C}-\mathrm{C})$ of PVDF
\end{tabular}

$v_{\mathrm{s}}=$ symmetrical stretching, $v_{\mathrm{a}}=$ asymmetrical stretching, $w=$ wagging and $t=$ torsional.

the PVDF-LiBOB electrolyte with different $\gamma$-ray doses. The band at $\sim 1153 \mathrm{~cm}^{-1}$ is assigned to PVDF. ${ }^{32}$ The band at $1169 \mathrm{~cm}^{-1}$ and $\sim 1202 \mathrm{~cm}^{-1}$ is assigned to $v_{\mathrm{s}}\left(\mathrm{CF}_{2}\right)+t\left(\mathrm{CH}_{2}\right)$ and $v_{\mathrm{a}}\left(\mathrm{CF}_{2}\right)+w\left(\mathrm{CF}_{2}\right)$ of PVDF, respectively. ${ }^{30}$ The band at $\sim 1190 \mathrm{~cm}^{-1}$ is assigned to the $\mathrm{C}-\mathrm{O}$ valence band out-of phase of LiBOB salt. It is observed that irradiation with $10 \mathrm{kGy}$ gamma dose of the PVDF-LiBOB electrolyte increased the intensity of PVDF characteristic bands. The intensity of the three bands at $\sim 1153, \sim 1169$ and $\sim 1202 \mathrm{~cm}^{-1}$ keeps increasing with increasing gamma doses until a maximum is achieved for the electrolyte irradiated with $35 \mathrm{kGy}$ of gamma radiation. Beyond this radiation dose, the intensity of the bands is observed to decrease. The intensity and the area of the band due to LiBOB characteristics at $\sim 1190 \mathrm{~cm}^{-1}$ are observed to decrease with increasing $\gamma$-ray dose until $35 \mathrm{kGy}$ of gamma radiation (Table 4). This can be attributed to further dissociation of LiBOB into ions. When the $\gamma$-dose is increased beyond $35 \mathrm{kGy}$, ion association takes place at a faster rate and the area and the intensity of the LiBOB peak are increased. This is also supported by FTIR deconvolution results as will be seen later.

Peng and $\mathrm{Wu}^{30}$ reported that the vibrational band corresponding to the amorphous nature of PVDF can be observed at
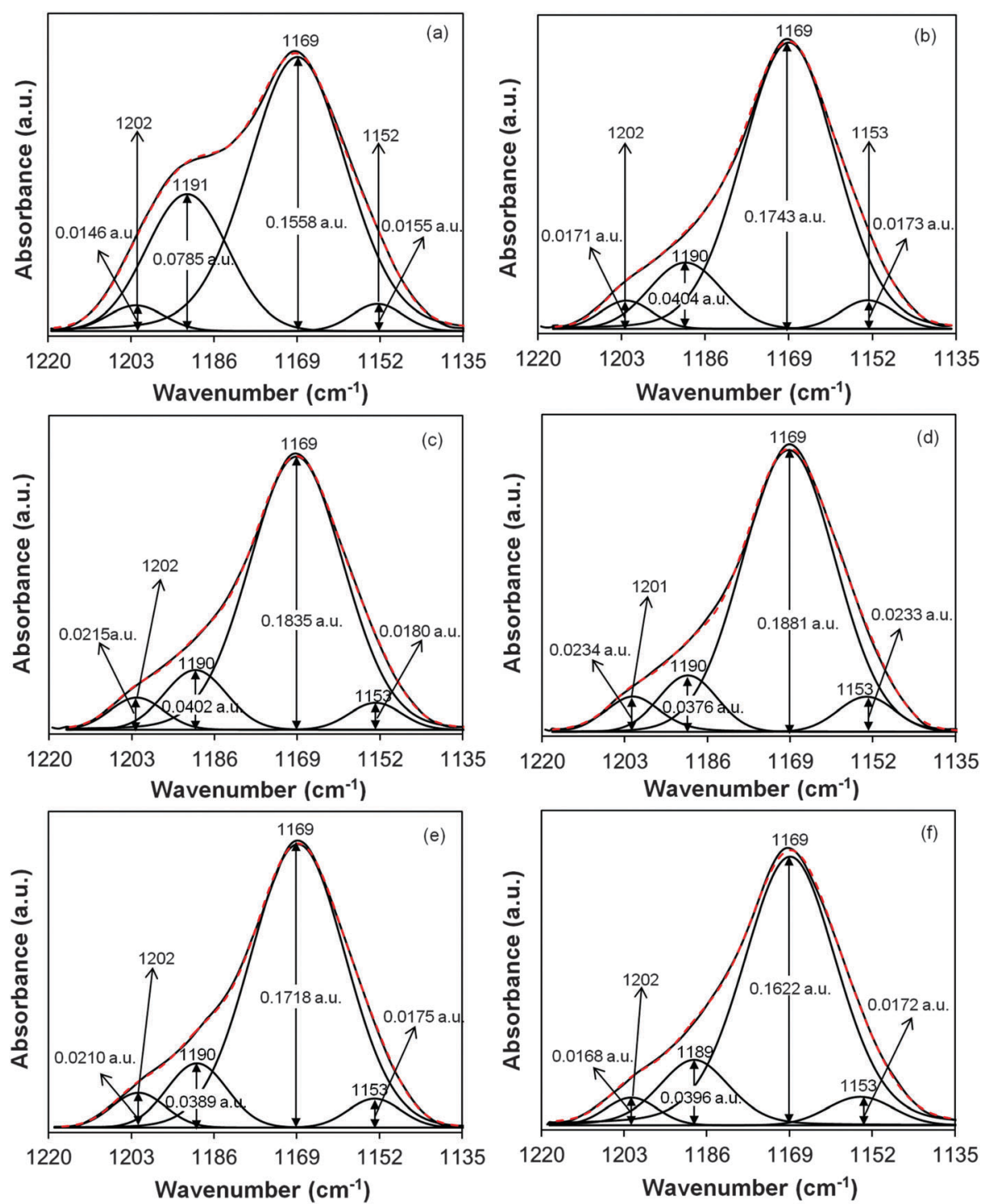

Fig. 6 FTIR deconvolution of PVDF-LiBOB electrolyte with (a) 0, (b) 10, (c) 25, (d) 35, (e) 40 and (f) 50 kGy $\gamma$-ray doses at band between 1220 and $1135 \mathrm{~cm}^{-1}$ 
Table 4 Area and intensity (in a.u.) of the FTIR band at $1190 \mathrm{~cm}^{-1}$ due to $\mathrm{C}-\mathrm{O}$ valence out-of phase of $\mathrm{LiBOB}$ salt

\begin{tabular}{lll}
\hline Doses (kGy) & Area $\left(\right.$ unit $\left.^{2}\right)$ & Intensity (a.u.) \\
\hline 0 & 1.6340 & 0.0785 \\
10 & 0.7399 & 0.0404 \\
25 & 0.6400 & 0.0402 \\
35 & 0.5600 & 0.0376 \\
40 & 0.6000 & 0.0389 \\
50 & 0.7479 & 0.0396
\end{tabular}

$904 \mathrm{~cm}^{-1}$. In this work, the band at $904 \mathrm{~cm}^{-1}$ has shifted to $876 \mathrm{~cm}^{-1}$. Fig. 7 shows the FTIR band between 905 and 850 wavenumbers. The area and the intensity of this band for every gamma dose are listed in Table 5. It is observed that the sample irradiated with $35 \mathrm{kGy}$ of $\gamma$-rays has the largest area and the highest intensity compared to other samples. This indicates that the sample exposed to $35 \mathrm{kGy}$ of $\gamma$-rays is the most amorphous sample, thus further strengthening the results estimated from DSC and XRD.

Fig. 8 shows the deconvolution of the FTIR spectra in the absorbance mode for all samples. The deconvoluted peaks are assigned following the report of Holomb et al. ${ }^{33}$ In Fig. 8, the band of free ions is observed at $1804 \mathrm{~cm}^{-1}$ and the band at $1812 \mathrm{~cm}^{-1}$ is due to contact ions of LiBOB salt. ${ }^{33}$ The area percentages of free ions and contact ions can be calculated from the ratio of the area
Table 5 Area and intensity (in a.u.) of the FTIR band between 905 and $850 \mathrm{~cm}^{-1}$ for PVDF-LiBOB with different $\gamma$-radiation doses

\begin{tabular}{lll}
\hline Doses (kGy) & Area $\left(\right.$ unit $\left.^{2}\right)$ & Intensity (a.u.) \\
\hline 0 & 3.8 & 0.215 \\
10 & 5.2 & 0.313 \\
25 & 5.6 & 0.339 \\
35 & 5.7 & 0.341 \\
40 & 5.4 & 0.321 \\
50 & 5.1 & 0.300
\end{tabular}

of free or contact ions to the total area of deconvolution peaks, respectively. Table 6 lists the percentage of free ions and contact ions of the PVDF-LiBOB electrolyte after exposure to different gamma-ray doses. The results are seen to support the change in the LiBOB peak area of Fig. 6 .

It is observed that the percentage of free ions in the electrolyte increased up to the sample irradiated with $35 \mathrm{kGy}$ of $\gamma$-rays. This implies that irradiation with gamma rays of the electrolytes causes more ions to dissociate, thus helping ion conduction. Beyond $35 \mathrm{kGy}$ of gamma irradiation, the percentage of free ions is observed to decrease. This may be attributed to ion association.

\subsection{Impedance spectroscopy (IS)}

The bulk impedance, $R_{\mathrm{b}}$, was extracted from the Nyquist plots. A typical set of Nyquist plots for samples irradiated with
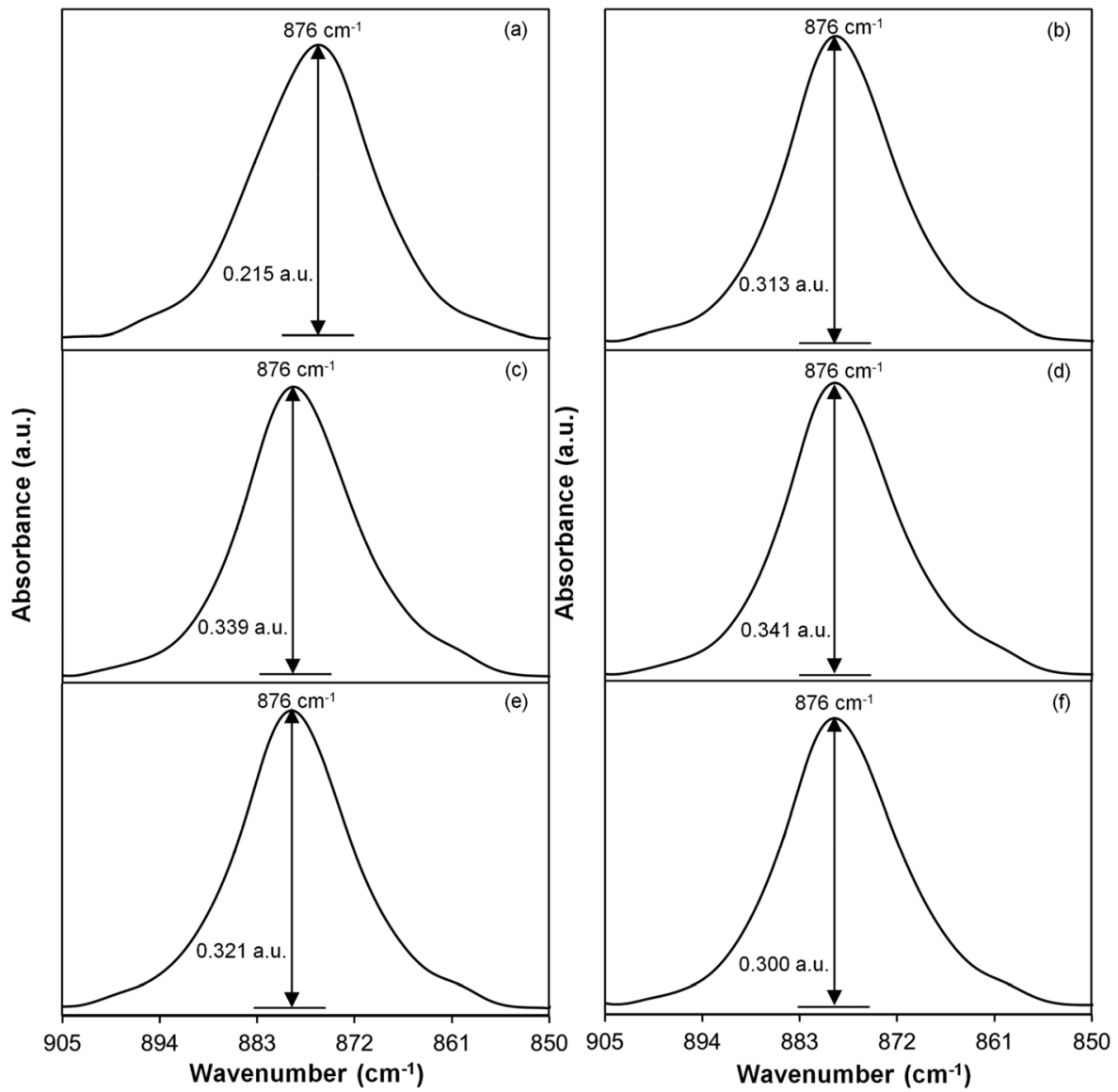

Fig. 7 FTIR spectral band of the PVDF-LiBOB electrolyte with (a) 0, (b) 10, (c) 25, (d) 35, (e) 40 and (f) 50 kGy $\gamma$-ray doses between 905 and $850 \mathrm{~cm}^{-1}$. 

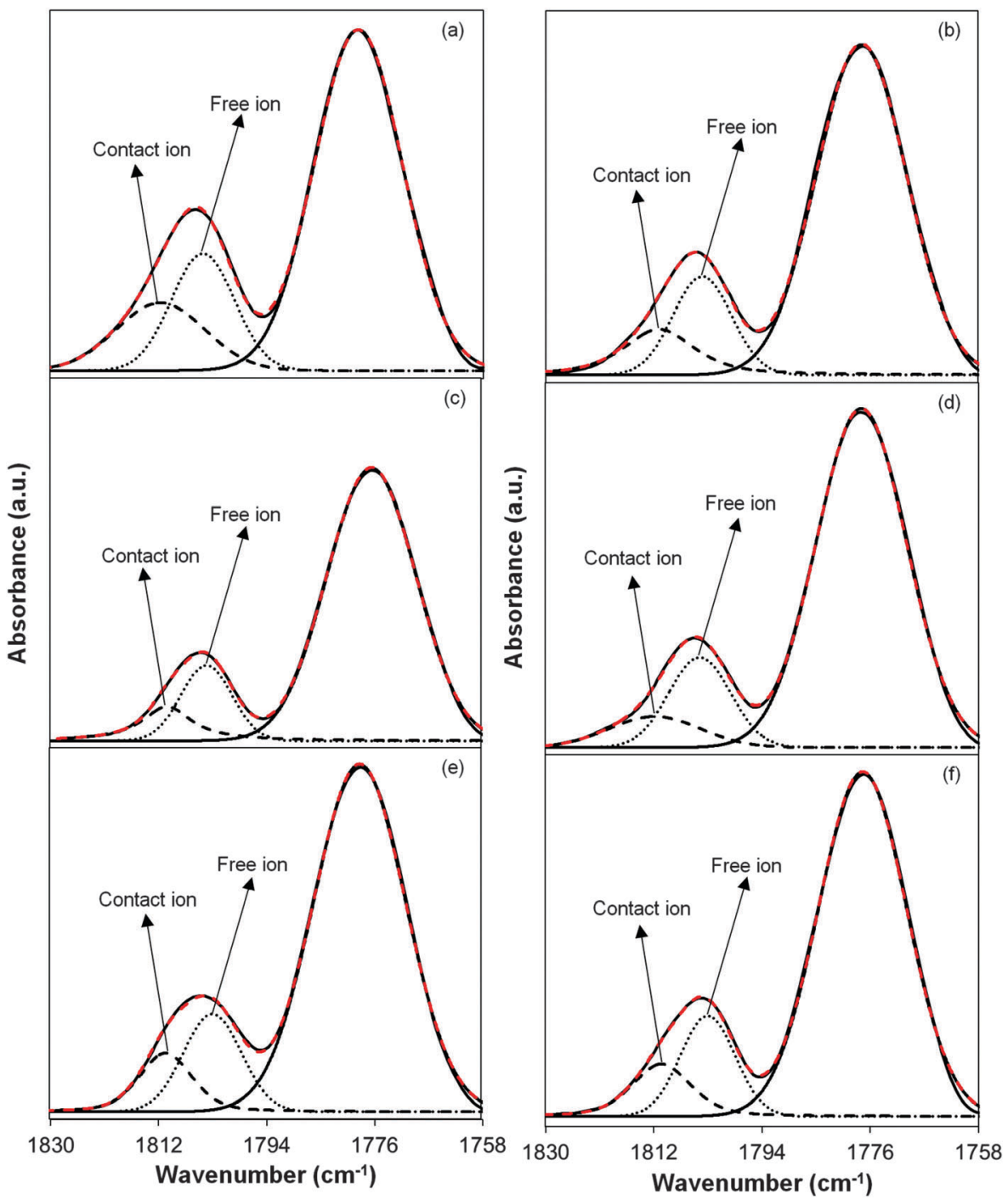

Fig. 8 FTIR deconvolution of the PVDF-LiBOB electrolyte with (a) 0, (b) 10, (c) 25, (d) 35, (e) 40 and (f) 50 kGy $\gamma$-ray doses.

Table 6 Area percentage of free and contact ions of the PVDF-LiBOB electrolyte with different $\gamma$-irradiation doses

\begin{tabular}{lll}
\hline Doses (kGy) & Free ions (\%) & Contact ions (\%) \\
\hline 0 & 55.18 & 44.82 \\
10 & 61.44 & 38.56 \\
25 & 63.61 & 36.39 \\
35 & 66.26 & 33.74 \\
40 & 62.69 & 37.31 \\
50 & 62.13 & 37.87
\end{tabular}

different gamma doses is shown in Fig. 9. The bulk impedance decreased upon increasing the $\gamma$-doses, and the lowest was recorded for the sample irradiated with $35 \mathrm{kGy}$ of $\gamma$-rays. The DC conductivity of the PVDF-LiBOB polymer electrolyte with different $\gamma$ doses is plotted as in Fig. 10. The non-irradiated sample has the lowest room temperature conductivity of $2.01 \times$ $10^{-5} \mathrm{~S} \mathrm{~cm}^{-1}$. Upon irradiation of the sample with $10 \mathrm{kGy}$ of $\gamma$-rays, conductivity increased to $2.30 \times 10^{-4} \mathrm{~S} \mathrm{~cm}^{-1}$ (about one magnitude order). The conductivity gradually increased with increasing $\gamma$-ray doses up to $3.05 \times 10^{-4} \mathrm{~S} \mathrm{~cm}^{-1}$ for sample irradiated with $35 \mathrm{kGy}$ of $\gamma$-rays. The conductivity is observed to decrease upon exposure to higher $\gamma$ doses. Compared to the non-irradiated sample, there is an overall increase in conductivity upon irradiation as shown in Table 7 .

The variation in conductivity can be related to the number density $(n)$, mobility $(\mu)$ and diffusion coefficient $(D)$ of charge carriers in the electrolyte. From the percentage variation of free ions with respect to the amount of dose obtained from FTIR deconvolution, the number density $(n)$, mobility $(\mu)$ and diffusion coefficient $(D)$ of charge carriers can be calculated using eqn (4)-(6). ${ }^{34}$

$$
\begin{gathered}
n=\frac{M \times N_{\mathrm{A}}}{V_{\text {Total }}} \times \text { free ions }(\%) \\
\mu=\frac{\sigma}{n e} \\
D=\frac{\mu k_{\mathrm{B}} T}{e}
\end{gathered}
$$




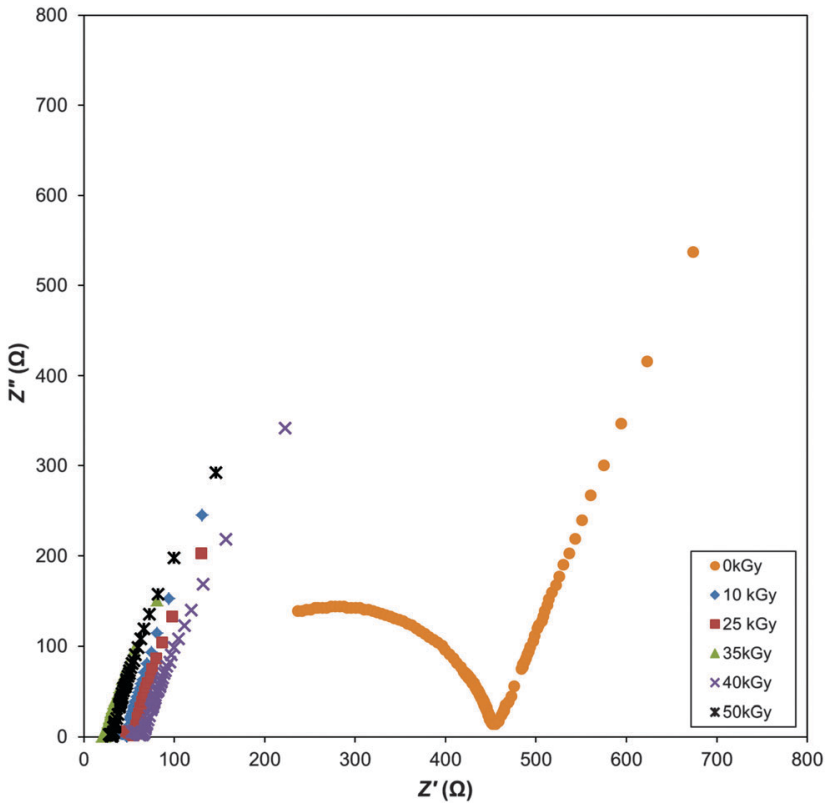

Fig. 9 Nyquist plot of the PVDF-LiBOB electrolyte irradiated with different $\gamma$-radiation doses at room temperature.

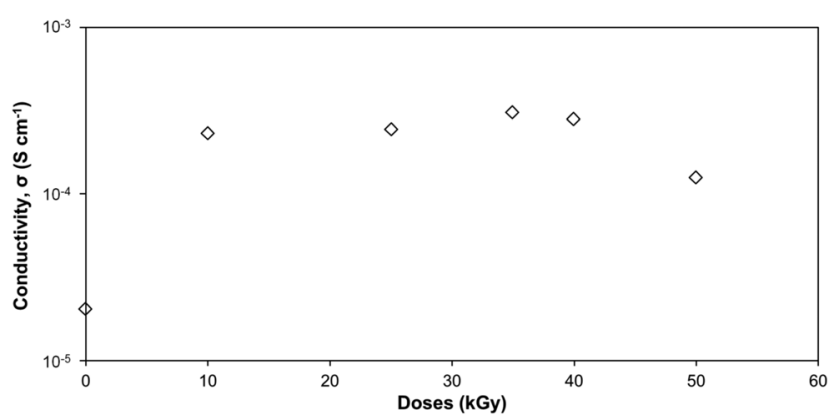

Fig. 10 The conductivity of the PVDF-LiBOB electrolyte irradiated with different $\gamma$-radiation doses.

The variation in the number density $(n)$, mobility $(\mu)$ and diffusion coefficient $(D)$ of free or mobile ions with $\gamma$ doses is shown in Fig. 11. The sample exposed to $35 \mathrm{kGy}$ of $\gamma$-rays exhibited the highest number density of mobile ions. This indicates that $\gamma$ irradiation has resulted in more free ions that can contribute to ionic conductivity. Samples irradiated with 40 and $50 \mathrm{kGy}$ of $\gamma$-rays showed a decrease in the number density of free ions that could have taken part in cross-linking or the formation of contact ions and larger aggregates that do not contribute to conductivity. ${ }^{35}$

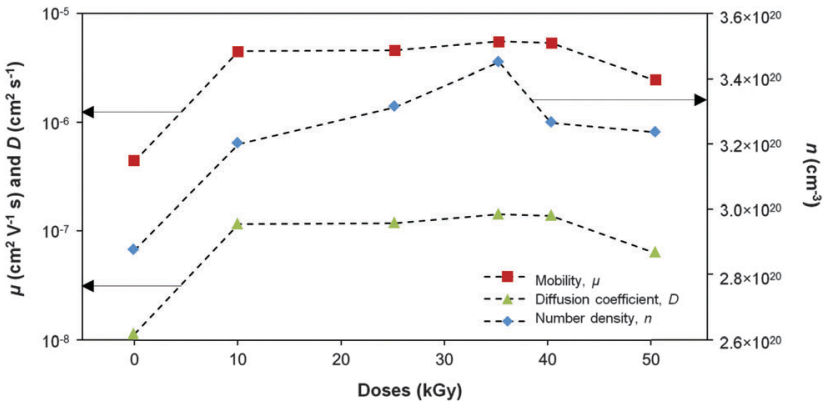

Fig. 11 The variation in the number density, mobility and diffusivity of charge carriers with different $\gamma$-doses.

This can be observed from the increase of the percentage of contact ions in the FTIR spectra.

The values for these parameters of number density $(n)$, mobility $(\mu)$ and diffusion coefficient $(D)$ free or mobile ions are listed in Table 7. It can be understood that the ionic conductivity is closely related to the number density of mobile ions. Gamma-ray irradiation also influences the ionic mobility and diffusion coefficient. It can be observed from Table 7 that conductivity variation with $\gamma$-ray doses is similar to the variation in $n, \mu$ and $D$ with increasing $\gamma$-ray doses. Hence, it can be inferred that $\gamma$-irradiation of the PVDF based electrolyte increased the dissociation of salt resulting in an increased number density of mobile ions, formed more amorphous phases leading to an increased ionic mobility and the diffusion coefficient of the mobile ions. Irradiating the electrolyte with greater than $35 \mathrm{kGy}$ of $\gamma$-radiation decreased the three parameters. This could be attributed to the ion association that led to increased crystallinity and glass transition temperature.

The frequency variation in the real part of AC conductivity is shown in Fig. 12 for different doses at room temperature. From Fig. 12, three frequency regions can be observed. The regions are low frequency dispersion region, frequency independent plateau region and high frequency region. The low-conductivity value at the low frequency dispersion region is related to the accumulation of ions due to the slow periodic reversal of the electric field. ${ }^{36}$ The intermediate region corresponds to the frequency independent plateau region from which the room temperature conductivity can be obtained ${ }^{37}$ and the high frequency dispersion region corresponding to a bulk relaxation phenomenon. The DC ionic conductivity has been calculated by extrapolating the plateau region to the vertical axis for each dose of the polymer electrolyte (Table 8). The maximum

Table 7 Calculated transport parameters of the PVDF-LiBOB electrolyte with different $\gamma$-irradiation doses

\begin{tabular}{llllll}
\hline $\begin{array}{l}\text { Doses } \\
(\mathrm{kGy})\end{array}$ & $\begin{array}{l}\text { Conductivity, } \\
\sigma\left(\mathrm{S} \mathrm{cm}^{-1}\right)\end{array}$ & $n\left(\times 10^{20} \mathrm{~cm}^{-3}\right)$ & $\mu\left(\times 10^{-6} \mathrm{~cm}^{2} \mathrm{~V}^{-1} \mathrm{~s}\right)$ & $n \mu\left(\times 10^{15} \mathrm{~cm}^{-1} \mathrm{~V}^{-1} \mathrm{~s}\right)$ & $D\left(\times 10^{-7} \mathrm{~cm}^{2} \mathrm{~s}^{-1}\right)$ \\
\hline 0 & $2.01 \times 10^{-5}$ & 2.87 & 0.44 & 0.13 & 0.11 \\
10 & $2.30 \times 10^{-4}$ & 3.20 & 4.49 & 1.44 & 1.15 \\
25 & $2.43 \times 10^{-4}$ & 3.31 & 4.58 & 1.52 & 1.18 \\
35 & $3.05 \times 10^{-4}$ & 3.45 & 5.52 & 1.74 & 1.42 \\
40 & $2.79 \times 10^{-4}$ & 3.26 & 5.34 & 0.79 & 0.63 \\
50 & $1.26 \times 10^{-4}$ & 3.24 & 2.43 & &
\end{tabular}




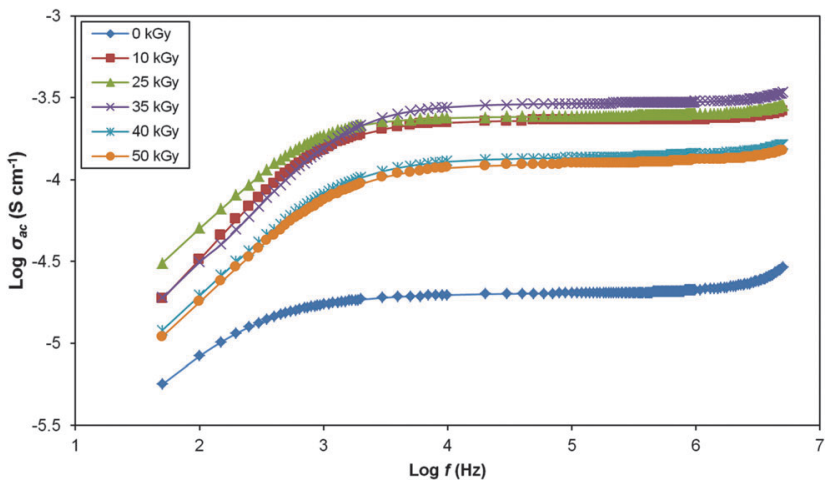

Fig. 12 The A.C. conductivity versus frequency of the PVDF-LiBOB electrolyte at different $\gamma$-radiation doses.

Table 8 An extrapolated graph of $\log (\sigma)$ ac versus log frequency

\begin{tabular}{ll}
\hline Doses $(\mathrm{kGy})$ & $\log \left(\sigma_{\mathrm{ac}}\right)$ \\
\hline 0 & -4.70 \\
10 & -3.64 \\
25 & -3.62 \\
35 & -3.54 \\
40 & -3.87 \\
50 & -3.91 \\
\hline
\end{tabular}

conductivity obtained from Fig. 12 is compatible with that reported in Fig. 11.

\section{Conclusions}

We obtained the results of PVDF-LiBOB polymer electrolyte films that were irradiated with $\gamma$-radiation to study the modification in ion conductivity induced by irradiation. The maximum conductivity was obtained for the sample irradiated with $35 \mathrm{kGy}$ of $\gamma$-rays which exhibited an ionic conductivity of $3.05 \times 10^{-4} \mathrm{~S} \mathrm{~cm}^{-1}$. From the Fourier transform infrared spectrum, each irradiated sample has been deconvoluted in the wavenumber region between 1830 and $1758 \mathrm{~cm}^{-1}$ in order to estimate the percentage of free and contact ions in the samples. The number density $(n)$, mobility $(\mu)$ and diffusion coefficient $(D)$ of the irradiated samples were found to increase with increasing $\gamma$-ray doses up to $35 \mathrm{kGy}$. Beyond this dose, values of these three parameters decreased. The sample irradiated with $35 \mathrm{kGy}$ of $\gamma$-rays is the most amorphous, represented by the lowest degree of cystallinity $\left(\chi_{\mathrm{c}}\right)$, glass transition temperature $\left(T_{\mathrm{g}}\right)$ and melting temperature $\left(T_{\mathrm{m}}\right)$. Since the $35 \mathrm{kGy} \gamma$-irradiated sample is most amorphous, it is easier for the ions to flow in this electrolyte thus increasing the conductivity.

\section{Acknowledgements}

The HIRG grant No. J-00000-73555 awarded by the University of Malaya is greatly appreciated and acknowledged.

\section{References}

1 O. Saito, in The Radiation Chemistry of Macromolecules, ed. M. Dole, Academic Press, New York, 1972, p. 223.

2 M. Sinha, M. M. Goswami, D. Mal, T. R. Middya, S. Tarafdar, U. De, S. K. Chaudhuri and D. Das, Ionics, 2008, 14, 323-327.

3 D. Fink, W. H. Chung, R. Klett, A. Schmoldt, J. Cardoso, R. Montiel, M. H. Vazquez, L. Wang, F. Hosoi, H. Omichi and P.-G. Langer, Radiat. Eff. Defects Solids, 1995, 133, 193-208.

4 D. Fink, R. Klett, L. T. Chadderton, J. Cardoso, R. Montiel, H. Vazquez and A. A. Karanovich, Nucl. Instrum. Methods Phys. Res., Sect. B, 1996, 111, 303-314.

5 M. F. Zaki, J. Phys. D: Appl. Phys., 2008, 41, 175404.

6 D. Sinha, K. L. Sahoo, U. B. Sinha, T. Swu, A. Chemseddine and D. Fink, Radiat. Eff. Defects Solids, 2004, 159, 587-595.

7 G. Kecskemeti, T. Smausz, N. Kresz, Zs. Toth, B. Hopp, D. Chrisey and O. Berkesi, Appl. Surf. Sci., 2006, 253, 1185-1189.

8 A. M. Basha, M. A. Ahmed, H. K. Marey and T. A. Hanafy, Indian J. Phys., A, 1996, 70, 619-625.

9 M. A. Ahmed, A. M. Basha, H. K. Marey and T. A. Hanafy, J. Appl. Polym. Sci., 2001, 79, 1749-1755.

10 T. A. Hanafy, Curr. Appl. Phys., 2008, 8, 527-534.

11 G. Boiteux, J. F. Chailan, J. Chauchard and G. Seytre, Nucl. Instrum. Methods Phys. Res., Sect. B, 1997, 131, 172-179.

12 Ma. E. Martinez-Pardo, J. Cardoso, H. Vazquez and M. Aguilar, Nucl. Instrum. Methods Phys. Res., Sect. B, 1998, 140, 325-340.

13 T. Phukan, D. Kanjilal, T. D. Goswami and H. L. Das, Nucl. Instrum. Methods Phys. Res., Sect. B, 1999, 155, 116-119.

14 E. Neagu, P. Pissis, L. Apekis and J. L. G. Ribelles, J. Phys. D: Appl. Phys., 1997, 30, 1551-1560.

15 L. Calcagno, G. Compagnini and G. Foti, Nucl. Instrum. Methods Phys. Res., Sect. B, 1992, 65, 413-422.

16 N. G. McCrum, B. E. Read and G. William, An Elastic and Dielectric Effects in Polymeric Solids, John Wiley, New York, 1967, pp. 501-520.

17 R. Kumar, S. A. Ali, U. De, D. K. Avasthi and R. Prasad, Indian J. Phys., 2009, 83, 963-968.

18 R. Ch. Abul-Hail, Journal of Basrah Researches (Sciences), 2010, 36, 6.

19 F. B. Dias, L. Plomp and J. B. J. Veldhuis, J. Power Sources, 2000, 88, 169-191.

20 V. Aravindan and P. Vickraman, Polym. Eng. Sci., 2009, 49, 2109-2115.

21 J. C. Li, C. L. Wang, W. L. Zhong, P. L. Zhang, Q. H. Webb and J. F. Webb, Vibrational mode analysis of $\beta$-phase poly(vinylidene fluoride), Appl. Phys. Lett., 2002, 81, 2223-2225.

22 S. R. Elliott, Adv. Phys., 1987, 36, 135-217.

23 T. Czvikovszky and H. Hargitai, Radiat. Phys. Chem., 1999, 55, 727-730.

24 A. Ghosh and A. Pan, Phys. Rev. Lett., 2000, 84, 2188-2190.

25 M. Hema, S. Selvasekerapandian, G. Hirankumar, A. Sakunthala, D. Arunkumar and H. Nithya, J. Phys. Chem. Solids, 2009, 70, 1098-1103. 
26 K. J. Zeleznak and R. C. Hoseney, The glass transition in starch, Cereal Chem., 1987, 64, 121-124.

27 M. M. Noor, M. A. Careem, S. R. Majid and A. K. Arof, Mater. Res. Innovations, 2011, 15, 157-160.

28 S. Wang, W. Qiu, T. Li, B. Yu and H. Zhao, Int. J. Electrochem. Sci., 2006, 1, 250-257.

29 N. Terinte, R. Ibbett and K. C. Schuster, Lenzinger Ber., 2011, 89, 118.

30 Y. Peng and P. Wu, Polymer, 2004, 45, 5295-5299.

31 B. Ahmed, S. K. Raghuvanshi, Siddhartha, N. P. Sharma, J. B. M. Krishna and M. A. Wahab, Progress in Nanotechnology and Nanomaterials, 2013, 2, 42-46.

32 M. Li, H. J. Wondergem, M.-J. Spijkman, K. Asadi, I. Katsouras, P. W. M. Blom and D. M. de Leeuw, Revisiting the $\delta$-phase of poly(vinylidene fluoride) for solutionprocessed ferroelectric thin films, Nat. Mater., 2013, 12, 433-438.

33 R. Holomb, W. Xu, H. Markusson, P. Johansson and P. Jacobsson, J. Phys. Chem. A, 2006, 110, 11467-11472.

34 A. K. Arof, S. Amirudin, S. Z. Yusof and I. M. Noor, Phys. Chem. Chem. Phys., 2014, 16, 1856-1867.

35 I. S. Noor, S. R. Majid and A. K. Arof, Electrochim. Acta, 2013, 102, 149-160.

36 A. S. A. Khiar, R. Puteh and A. K. Arof, Phys. B, 2006, 373, 23-27.

37 E. Barsoukov and J. R. Macdonald, Impedance spectroscopy, theory experiment and applications, Wiley-Interscience, New York, 2005. 